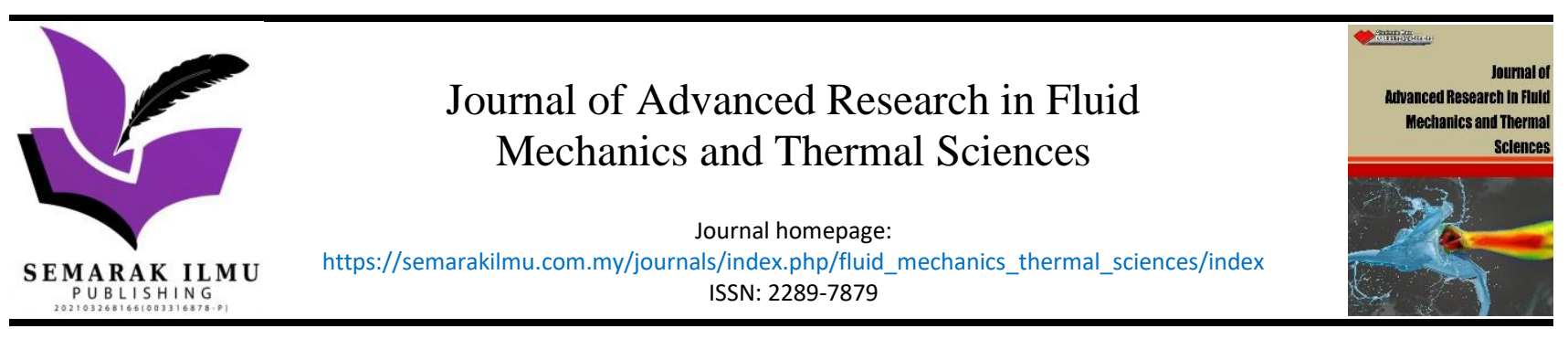

\title{
Static Analysis of Unsteady Aerodynamics Wake of Simplified Helicopter Model Via Simulation Work
}

\author{
Nurain Othman ${ }^{1, *}$, Iskandar Shah Ishak ${ }^{1}$, Md. Nizam Dahalan ${ }^{1}$ \\ 1 School of Mechanical Engineering, Faculty of Engineering, Universiti Teknologi Malaysia, 81310 Skudai, Johor, Malaysia
}

\section{ARTICLE INFO}

\section{Article history:}

Received 24 March 2021

Received in revised form 19 October 2021

Accepted 25 October 2021

Available online 25 November 2021

\section{Keywords:}

Static analysis; turbulence model; computational fluid dynamics; unsteady wake; simplified model

\section{ABSTRACT}

\begin{abstract}
Computational tools have led and helped researchers in providing advanced results, notably in rotorcraft research, as flow around the helicopter is dominated by complex aerodynamics and flow interaction phenomena. This research work aimed to evaluate the aerodynamic computational results on a simplified model helicopter when the model was subjected to the angles of attack $0^{\circ},-5^{\circ},-15^{\circ}$, and $-20^{\circ}$, respectively. The study also examined the unsteady flow behaviour on the three-dimensional elliptical shape of a fuselage equipped with a rotor hub of the single rotor blade. The computational domain for the aerodynamic flow field was created within the size of $7 \mathrm{~m}$ (length) $\mathrm{x} 5 \mathrm{~m}$ (width) $\mathrm{x}$ $5 \mathrm{~m}$ (height). Results showed that an increase in the angle of attack in the rotor component caused additional drag of about $34 \%$ to $45 \%$ whilst the fuselage component contributed about $55 \%$ to $65 \%$ to drag increment. Also, a significant value of total pressure from -235 $\mathrm{Pa}$ to $250 \mathrm{~Pa}$ demonstrated along the simplified model helicopter distinctly showed that the complexity of geometry caused adverse pressure. The findings of this research work could potentially improve the understanding of complex flow surrounding the helicopter that has always baffled the aerodynamicists.
\end{abstract}

\section{Introduction}

Tail shake has become an issue since the creation of helicopters. It causes tremors on the structure of the helicopter performance, occupant comfort and pares the handling and responsive quality of the helicopter [1]. The unsteady wake produced contains large eddy motions that are shed downstream along the tail boom of the helicopter and create an irregular frequency on the tail rotor. This phenomenon is called the tail shake phenomenon. It especially occurs in conventional helicopter configuration with a single main rotor and is the result of interaction between the turbulent rotor and fuselage wake with the near airframe [2].

The time spent in the flight of an aircraft is as important as the condition itself [1]. A fixed-wing one manoeuvre goes into one incremental load, but helicopter, a manoeuvre results in a series of several incremental load cycles [3]. The helicopter consists of a complex combination of geometries compare to fixed wing.

\footnotetext{
*Corresponding author.

E-mail address: nurainbo46@gmail.com
}

https://doi.org/10.37934/arfmts.89.1.142153 
The unsteady wake is not just caused by the states of flight of the helicopter but also the geometries structure. It could be seen to produce a certain value of drag at a different angle of attack. The creation of a pressure differential over the wing surface or, in this case, where the rotor and the main-rotor hub formed turbulence [4]. There were many justifications written on the complexity of aerodynamics acted on the helicopter that was characterised as unsteady wake [5].

Factors such as rotor hub fairing, engine exhaust and cowling, shape, position, and dynamics of the tail boom play an important role in the tail shake phenomenon [2]. Main-rotor-hub has been said to contribute $25 \%-30 \%$ of vehicle parasite drag [6]. One-third of the total drag acts on the conventional helicopter was attributed to the rotor hub [7]. It had also been said that the installation of the propeller had significant effects on the data and increased the absolute value of pressure coefficient and vortex strength [8]. The drag generated depending on the size or reference area of the object and the complexity of the shape. It was an aerodynamics force that relied on the pressure variation of air acted around the body as the object moved through the air [9]. Reducing the drag of the main rotor hub was essential in developing an efficient, low fuel emission helicopter. However, this condition was still hard to predict before the flight test [10]. This rotor-fuselage interaction had been documented during the prototype stage of aircraft design for EH-101 and AH-64D [5,11].

Static analysis was considered to be the simplest way especially in Computational Fluid Dynamic (CFD) where it reduced the operation time of the simulation. Data collected were easier to be compared to experimental or simulation rather than dynamic analysis. Moreover, static analysis was referred to as a medium for guiding the project to more advanced and complex research. Using a simpler model of a helicopter with simpler geometries, helped in time and also significantly distinct the effect of drag acted on the main rotor hub. A significant change of contour in the form of total pressure and turbulent intensity could be seen from the different flight conditions. An angle of $-5^{\circ}$ angle of attack was chosen for total pressure and turbulent intensity collections of data. This angle of attack influenced the trajectories of the wake produced and normally the longest flight segment occurred also happened at nose down configuration [12]. From the simulation, the formation of turbulent could be valued and visualised, sourced out from rotor and fuselage components due to the complexity of geometries on the simplified model helicopter. This proved that most disturbances of flow occurred on and surrounded the rotor and fuselage whereas these disturbances would be "carried away" forming what was so-called an aft flow turbulent.

This paper aimed to analyse static analysis based on the drag coefficient and drag force for an angle of attack of $0^{\circ},-5^{\circ},-15^{\circ}$, and $-20^{\circ}$ and total pressure, and turbulent intensity for $-5^{\circ}$ angle of attack produced from the geometries of the simplified model especially in the main rotor hub area. Ansys software was used for the simulation to see the effect of the wake created down the flow of the simplified model.

\section{Methodology}

\subsection{Simulation Framework}

This section discusses the simulation framework that was done through the dimension of a domain, simplified model, the shape of a pylon, grid-independent study at $-15^{\circ}$ angle of attack, and turbulence model.

\subsubsection{Computational fluid model}

This simulation was run using an elliptical model of a simplified model helicopter (Figure 1) that was attached to the single main rotor of two blades. The model was with longitudinal axes ratio to 
latitude axes ratio of 4.485 [13]. Ellipsoidal fuselage avoided geometric complexity and maintained the primary flow characteristic of a helicopter's fuselage. Longitudinal axes were set to be $660 \mathrm{~mm}$ and lateral axes to be $147 \mathrm{~mm}$.

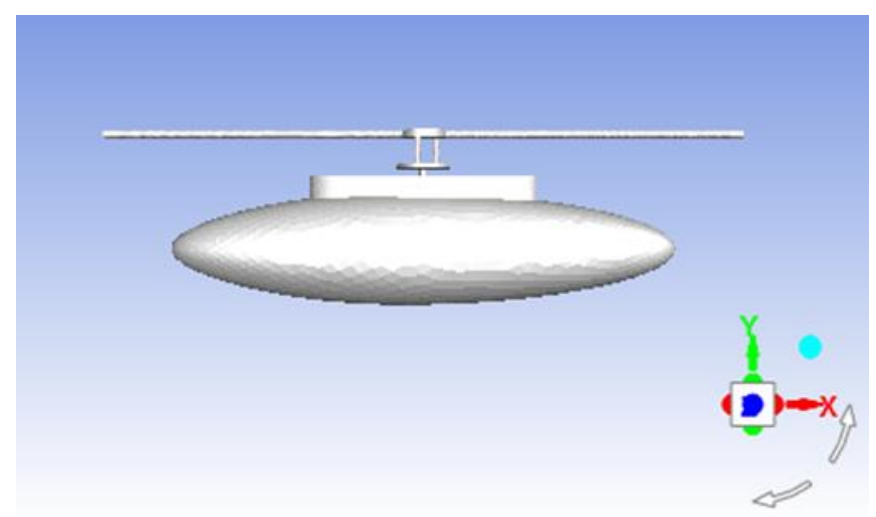

Fig. 1. Simplified model helicopter used for cfd simulation

The helicopter was known to be in the flight state nose-down position during forward-flight. Therefore, the simulation was run to investigate the effect of the main rotor hub structure on the formation of unsteady wake at a different angle of attack. Even if there was no tail rotor-fuselage interaction shown due to the lack of tail boom and tail rotor. However, through data of the drag force, coefficient, and contour of turbulent intensity, the effect of the unsteady wake generated will be compared between angles of attack.

Figure 2 shows the dimensions of the main rotor hub that were selected to display the presence of adverse pressure along with the geometries of the hub at the angles of attack of $0^{\circ},-5^{\circ},-15^{\circ}$, and $-20^{\circ}$.

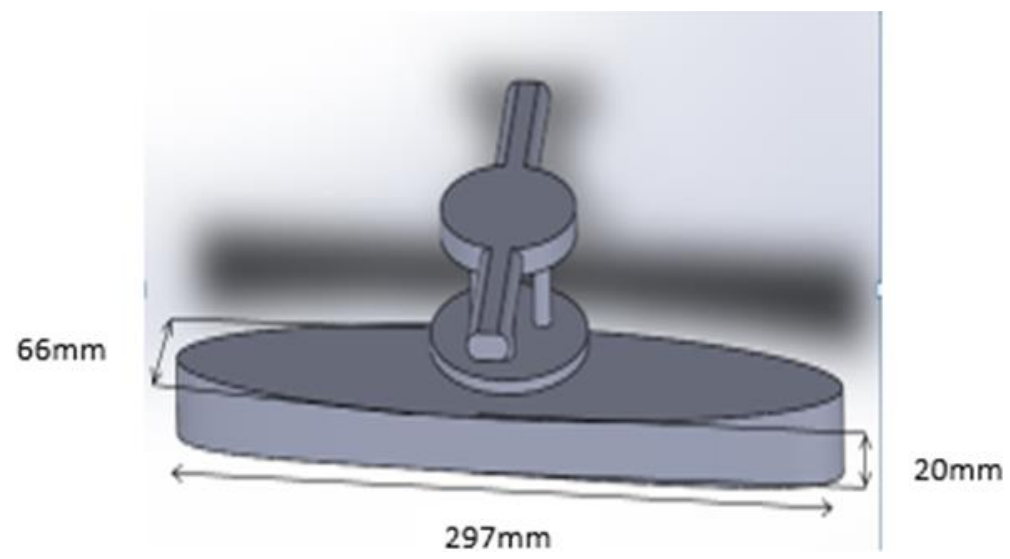

Fig. 2. Pylon configuration selected for the simplified model

Pylon configuration was one of the main sources of the generation of drag. The main rotor hub caused an increase in drag by $230 \%$ around the fuselage [14]. The parasite drag was supported by another researcher stated in an experimental paper on fuselage drag where the existence of the main rotor hub caused the increase of drag by from $48 \%$ at an angle of attack of $-10^{\circ}$ to $62 \%$ between $0^{\circ}$ to $10^{\circ}$ [15]. It was also stated that the main rotor hub was a major contribution to the tail shake phenomenon where the unsteady wake caused the tremor on the vertical tail, which produced vibration along with the tail boom, which reduced the performance and responsive quality [11]. 
The tail I shake phenomenon likely happened when there was forward velocity as the stream needed to 'carry' the main rotor hub assembly's wake [16]. Furthermore, it is supported by another researcher whereby $70 \%$ of the total drag was from the fuselage and the remaining $30 \%$ was due to the rotor head itself [17].

Grid generation proved to be vital in computational numerical solutions. A well-constructed mesh made a significant difference in the result. It removed problems that lead to instability or lack of convergence also increased to produce the result that was almost accurate or precise for which the final solution was from experiments [18]. Figure 3 shows the grid-independent study that was done at $\mathrm{a}-15^{\circ}$ angle of attack.

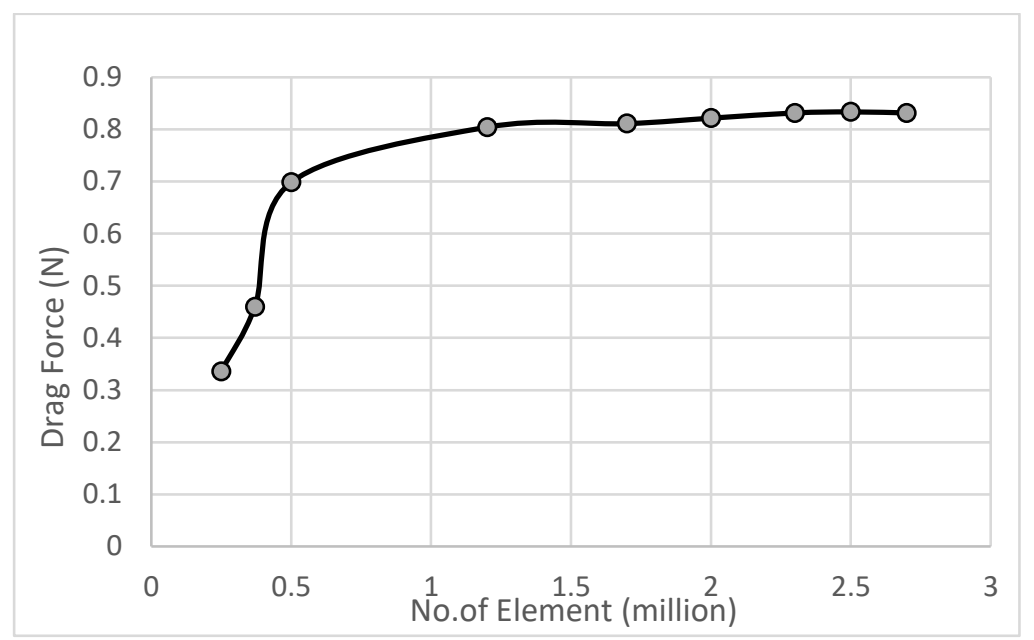

Fig. 3. Grid-Independent study at $15^{\circ}$ angle of attack

Figure 3 shows a grid-independent study that was done at a $15^{\circ}$ angle of attack. The result showed that at 1.7 million of the number of elements shown to be produced an insignificant difference of value compared to 3.0 million number of elements. A simplified model was then meshed using unstructured mesh to help improve the grid quality. The unstructured mesh had higher flexibility, which was allowed in the matching cells, especially in highly curved boundaries [18]. The grid generated on certain models should be sufficient enough to produce adequate resolution on flow and geometry structure based on the number of mesh, type, and quality of the mesh.

For this simulation, 2.5 million elements were involved in grid generation and skewness of 0.843 . Three million number of the element was not selected for this simulation due to the number of skewness that was more than 0.9. Even though it produced a result of close to 2.5 million, but it had degenerated cells during static analysis. It was stated that mesh in most flows must be kept at 0.95 and below to avoid any convergence difficulties [19]. High skewness was not recommended to avoid degenerate cells. Mesh quality metrics between 0.8-0.95 were acceptable [20]. Figure 4 shows the grid generated for static simulation of the two-blade rotor of a simplified model. The grid generated mostly focused on the mesh part of the rotor and fuselage.

From Figure 4, it could be seen that the grid was generated close to the selected variable required. The number of cells within the computational domain strongly influenced the accuracy of the Computational Fluid Dynamic solution and maneuvered to achieve convergence [18]. However, the generation of the grid was highly dependent and limited to computational costs and calculation turnover and the majority of the time was devoted to generating meshes [18]. 


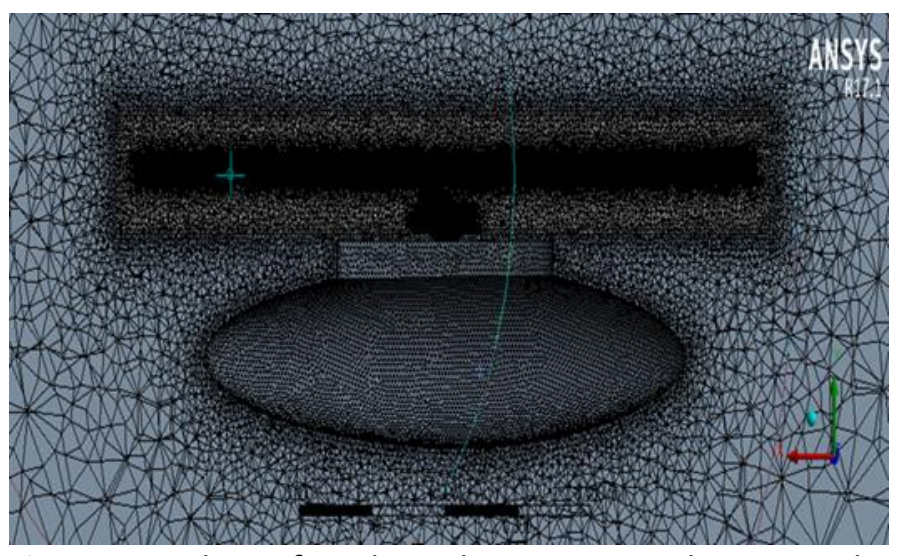

Fig. 4. Number of grids and interactions between the stator and rotor parts

\subsubsection{Computational fluid dynamic solver}

To solve the structure's equation of motion, a Reynold Average Navier-Stokes (RANS) model was selected. RANS model was the largest in the field of turbulence. The $k-\varepsilon$ model was used to solve between two variables of turbulent kinetic energy, $k$, and rate of dissipation of kinetic energy, $\varepsilon$. This technique offered good convergence with low computer memory [21]. Moreover, this model was usually used for the external flow of complex geometries [21]. However, a k- $\omega$ turbulence model was selected. The $k-\omega$ turbulence modelling was an advancement of the $k-\varepsilon$ model. It was more accurate than the $k-\varepsilon$ model. The $k-\omega$ model could predict shear -stresses of adverse pressure gradient boundary layers. Moreover, it may be applied throughout the boundary layer without further modification [21].

\section{Results}

\subsection{Aerodynamics Forces}

This section discussed the results obtained from the simulations. The effects of angle of attack based on the drag force and coefficients, total pressure and turbulent intensity were discussed.

\subsubsection{The effect of angle of attack on drag force and coefficient}

The same dimension of the simplified model was used at a different angle of attack. The obtained drag force at different angles of attack was tabulated in Table 1, where it was the result value to drag coefficient using Eq. (1):

$C d=\frac{2 D}{A \rho V^{2}}$

where the coefficient of drag, $C d$, the density of air taken at $1.225 \mathrm{~kg} / \mathrm{m}^{3}, \rho$, drag force, $D$, the velocity of free stream flow, $V$ at $20 \mathrm{~m} / \mathrm{s}$ and frontal area of $0.0179 \mathrm{~m}^{2}$. Drag force was calculated based on two distinctive components, which were rotor and fuselage. It was then calculated to see the significant difference in the percentage of drag coefficient produced on the two-component and see if the values were compatible with the data collected from other researchers. 
Table 1

Drag force calculated from four different angles of attack

\begin{tabular}{llll}
\hline Components & Angle of Attack & Drag Force $(\mathrm{N})$ & $\begin{array}{l}\text { Drag Force } \\
\text { Percentage (\%) }\end{array}$ \\
\hline Fuselage & 0 degree & 0.445 & 55.192 \\
Rotor & & 0.361 & 44.808 \\
Fuselage & -5 degree & 0.466 & 57.386 \\
Rotor & & 0.346 & 42.614 \\
Fuselage & -15 degree & 0.520 & 60.357 \\
Rotor & & 0.342 & 39.643 \\
Fuselage & -20 degree & 0.580 & 63.422 \\
Rotor & & 0.334 & 36.578 \\
\hline
\end{tabular}

A significant increase in value for drag force between $-5^{\circ}$ and $-15^{\circ}$ angles of attack for fuselage component and reduction for the rotor component was shown in Table 1 . The frontal area of the fuselage increased as the simplified model tilted down at a different angle of attack, hence the increasing values of drag force. The result in Table 1 was supported by Khier $[7,14]$, Raghav et al., [6], Stepanov et al., [15], and Batrakov et al., [17]. The existence of the main rotor hub caused the increase of drag by from $48 \%$ at an angle of attack of $-10^{\circ}$, while the result tabulated in 1 showed $57.39 \%$ on the fuselage and $42.61 \%$ on the rotor at $-5^{\circ}$ angle of attack [15].

Meanwhile, Stepanov et al., [15] stated that the drag force of $62 \%$ between $0^{\circ}$ to $10^{\circ}$ was compared with the result tabulated, showed variant by $4.62 \%$, from the drag force at $-5^{\circ}$, of $57.39 \%$. Moreover, it was indicated that almost $70 \%$ of the total drag was from the fuselage and the remaining $30 \%$ was due to the rotor head itself $[6,17]$. Results showed that each rotor component simulated at each angle of attacks produced a percentage drag force of more than $30 \%$ with a variance range from $17.98 \%$ to $33.04 \%$. The data produced a dissimilar due to differing dimensions and models of helicopter used between real detailed helicopter geometry and a simplified model. Drag force could be shown through the contour of the total pressure diagram and proved the existence of unsteady wake acted on the simplified model. Table 2 illustrates the drag coefficient and percentages reduction for each and between fuselage and rotor calculated using Eq. (1).

Table 2

Drag coefficient at a different angle of attack

\begin{tabular}{llll}
\hline Components & Angle of Attack & $\begin{array}{l}\text { Drag Coefficient } \\
(\mathrm{Cd})\end{array}$ & $\begin{array}{l}\text { Percentage } \\
\text { Reduction (\%) }\end{array}$ \\
\hline Fuselage & 0 degree & 0.1014 & 18.79 \\
Rotor & & 0.08235 & \\
Fuselage & -5 degree & 0.10619 & 25.74 \\
Rotor & & 0.07886 & \\
Fuselage & -15 degree & 0.11863 & 34.32 \\
Rotor & & 0.07792 & \\
Fuselage & -20 degree & 0.13209 & 43.32 \\
Rotor & & 0.07619 & \\
\hline
\end{tabular}

The drag coefficient increased as the simplified helicopter tilted downward. The increase in the angle of attack gradually increased the drag coefficient of the fuselage component but reduced the drag coefficient of the rotor blade. This showed the positioning of the model that produced the highest frontal area would create big drag.

Table 2 shows the value of the percentage difference between the fuselage and rotor at a different angle of attack. As the angle of attack increased, the percentage increased displayed the increments of drag coefficient as the simplified model in a nose-down position. It was proven that 
the evidence at higher pitch angles the drag coefficient was proven to surge. However, drag was also dependent on the frontal area of the component exposed to the forward flow of the air stream and it showed similar trend production of drag gain on the fuselage component shown tabulated in Table 1. Figure 5 and Figure 6 show the focus areas that significantly showed the distinct changes of total pressure and turbulent intensity acted on the surface of the rotor and fuselage at $-5^{\circ}$ angle of attack.

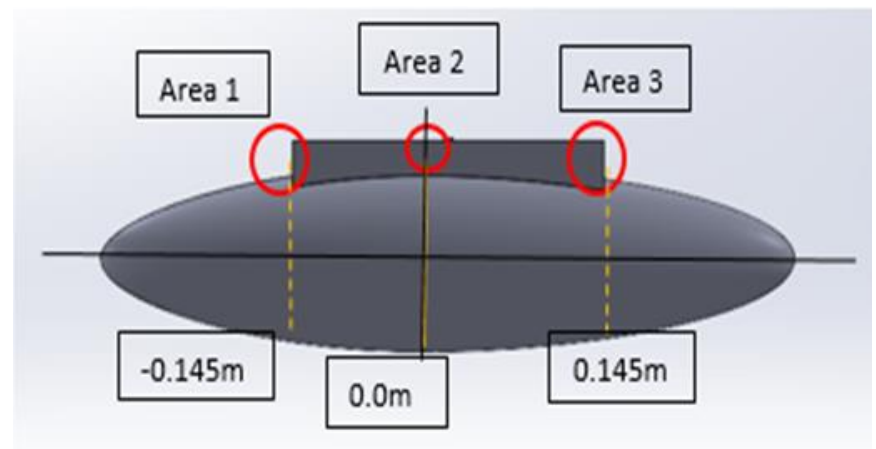

Fig. 5. Simplified model of a fuselage

Figure 5 shows a few areas that were chosen to demonstrate the significant changes in total pressure and turbulent intensity. It was significant to see that due to the geometry of the fairing component, it disturbed the air free streamflow in the system. Areas 1, 2, and 3 were targeted at the range location of $-0.145 \mathrm{~m}, 0 \mathrm{~m}$, and $0.145 \mathrm{~m}$ with $\pm 0.003 \mathrm{~m}$. The tolerance was used to show the increments of total pressure and turbulent intensity at a certain distance.

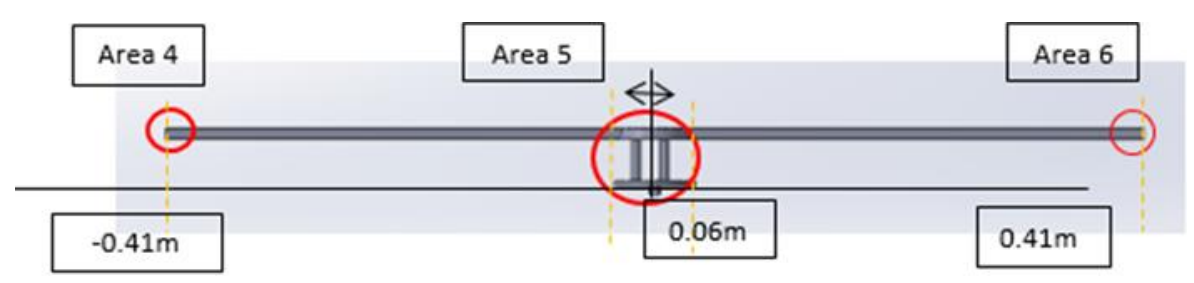

Fig. 6. Simplified model of blade stubs

Figure 6 focuses on the areas 4, 5, and 6 on simplified model two rotor blade stubs by increments of $\pm 0.003 \mathrm{~m}$, where it shows the flow of air surrounded the rotor components.

In the same investigation done by Ishak et al., [22], it was found that the highest turbulent intensity happened as well at this particular angle of attack, which was $-5^{\circ}$. Therefore, Figure 7 shows that the value of total pressure and turbulent intensity of fuselage and rotor acted at $-5^{\circ}$ angle of attack for this paper.

Figures expressed the real dimension and position of the fuselage and rotor scale along the $x$-axis only. These features were used to help exhibit the effects of total pressure and turbulent intensity on the complexity of geometries presented on the fairing, components of fuselage and rotor. An insignificant increase value of total pressure acted at $-0.142 \mathrm{~m}$. Meanwhile, a notable pressure drop was shown at $0.142 \mathrm{~m}$. Further details and discussion of the value of total pressure and turbulent intensity were tabulated in Table 4. 


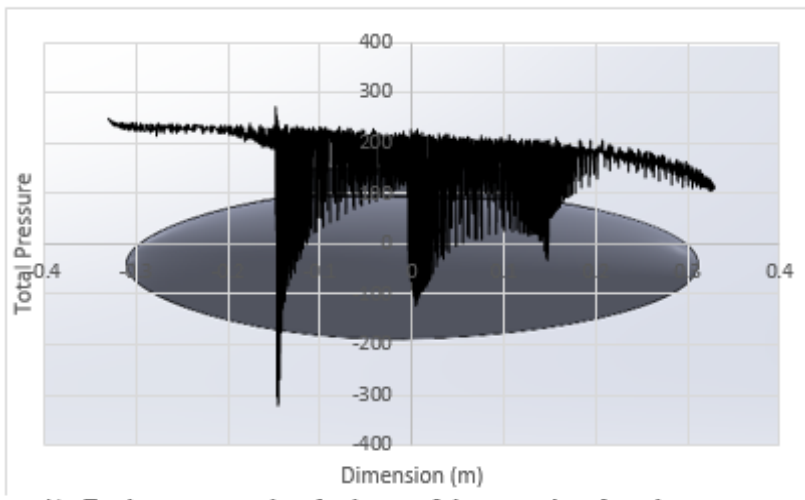

A) Total pressure acted on fuselage at -5 degree angles of attack

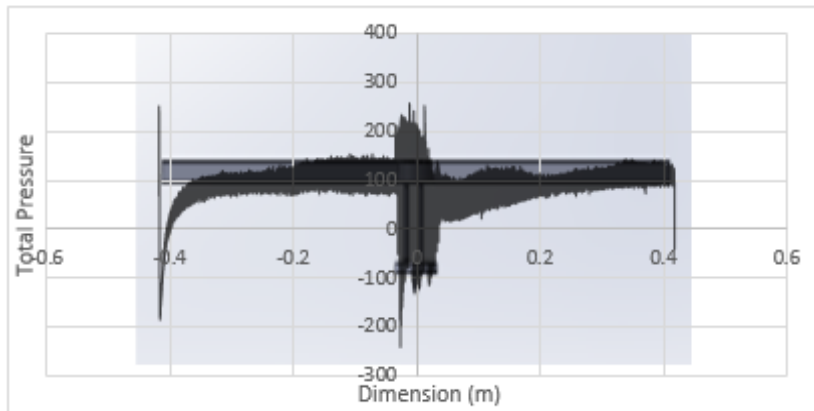

B) Total Pressure acted on rotor at -5 degree angles of attack.

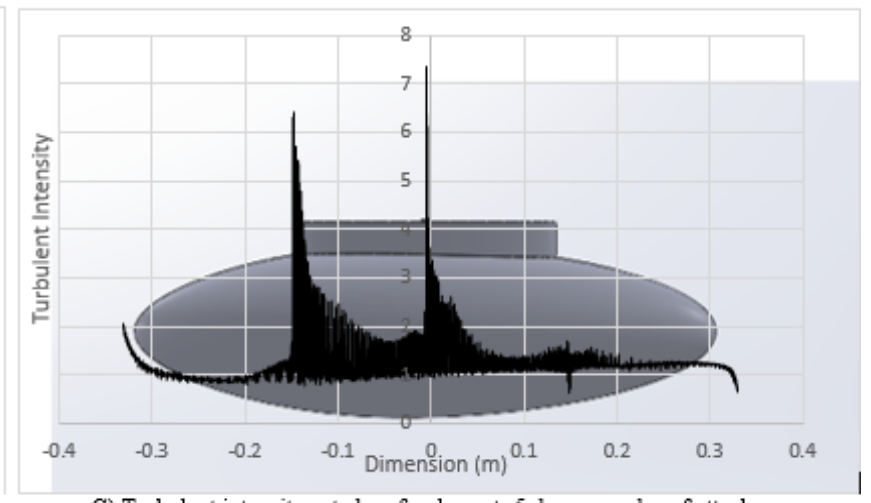

C) Turbulent intensity acted on fuselage at -5 degree angles of attack

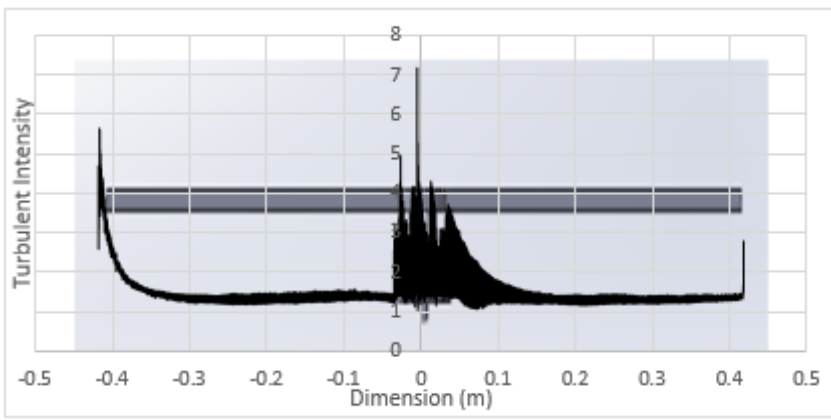

D) Turbulent intensity acted on rotor at -5 degree angles of attack.

Fig. 7. Total pressure and turbulent intensity acted on the fuselage and rotor on $5^{\circ}$ angle of attack

Figure 7 presents the collected values that show graphically the intensified jagged values of total pressure presented in Figure $7(\mathrm{~A})$ and a distinct increase of turbulent intensity on $-0.145 \mathrm{~m}$ and $0.148 \mathrm{~m}$. Details of the values were tabulated in Table 3 and Table 4 and simplified in graphs in Figure 8.

Table 3 and Table 4 exhibit the collected data from the chosen area of Figure 5 and Figure 6 with increments of $\pm 0.003 \mathrm{~m}$. The data collected focused on three parts which compromised the fuselage, rotor, and both. The increments were used to display the value changes produced before and after the flow passed by the geometries on fairing and rotor. It was shown that total pressure acting on both fuselage and rotor produced values from -235 Pa to $250 \mathrm{~Pa}$ with the highest turbulent intensity between 10.76 to 13.29 .

\section{Table 3}

Data collected of total pressure and turbulent intensity for fuselage at $-5^{\circ}$ angle of attack

\begin{tabular}{lllll}
\hline $\begin{array}{l}\text { Area } \\
( \pm 0.003 \mathrm{~m})\end{array}$ & $\begin{array}{l}\text { Total Pressure } \\
(\mathrm{Pa})\end{array}$ & $\begin{array}{l}\text { Turbulent } \\
\text { Intensity }\end{array}$ & $\begin{array}{l}\text { Total } \\
\text { Pressure }(\mathrm{Pa})\end{array}$ & $\begin{array}{l}\text { Turbulent } \\
\text { Intensity }\end{array}$ \\
\hline $\begin{array}{l}\text { Fuselage } \\
-0.142\end{array}$ & -177.10 & 5.41 & $\begin{array}{l}\text { Fuselage + Rotor } \\
-0.96 .90\end{array}$ & 6.90 \\
-0.145 & -316.83 & 5.67 & -230.58 & 7.15 \\
-0.148 & 56.34 & 6.29 & 139.78 & 7.77 \\
-0.003 & -41.61 & 6.11 & -163.11 & 10.76 \\
0 & 34.53 & 3.05 & 142.10 & 5.15 \\
0.003 & -115.82 & 2.96 & -235.27 & 6.27 \\
0.142 & 25.03 & 1.38 & 76.14 & 2.90 \\
0.145 & 0.10 & 1.46 & 48.31 & 2.94 \\
0.148 & -20.58 & 1.45 & 27.97 & 2.93 \\
\hline
\end{tabular}


Table 4

Data collected of total pressure and turbulent intensity for rotor at $-5^{\circ}$ angle of attack

\begin{tabular}{lllll}
\hline $\begin{array}{l}\text { Area } \\
( \pm 0.003 \mathrm{~m})\end{array}$ & $\begin{array}{l}\text { Total Pressure } \\
(\mathrm{Pa})\end{array}$ & $\begin{array}{l}\text { Turbulent } \\
\text { Intensity }\end{array}$ & Total Pressure $(\mathrm{Pa})$ & $\begin{array}{l}\text { Turbulent } \\
\text { Intensity }\end{array}$ \\
\hline & Rotor & & Fuselage + Rotor & \\
-0.407 & -42.59 & 3.36 & -42.59 & 3.36 \\
-0.410 & 250.10 & 5.61 & 250.10 & 5.61 \\
-0.413 & -92.10 & 4.34 & -92.10 & 4.34 \\
-0.003 & -121.50 & 7.18 & -163.11 & 13.29 \\
0 & 107.60 & 2.10 & 142.13 & 5.14 \\
0.003 & -119.45 & 3.31 & -235.27 & 6.27 \\
0.407 & 129.90 & 1.45 & 129.90 & 1.45 \\
0.410 & -41.04 & 2.77 & -41.40 & 2.77 \\
0.413 & 90.75 & 1.46 & 90.75 & 1.46 \\
\hline
\end{tabular}

Figure 8 displays the straightforward graph of the data from Table 3 and Table 4 . As the simplified model nose-down during the simulation, the total pressure proved to be increased. The same goes for turbulent intensity. The angle of attack of $-5^{\circ}$ was shown to produce a high value of total pressure at $-0.145 \mathrm{~m}$. Hence, Figure 11 and Figure 12 represented the contour of total pressure and turbulent intensity at $a-5^{\circ}$ angle of attack.

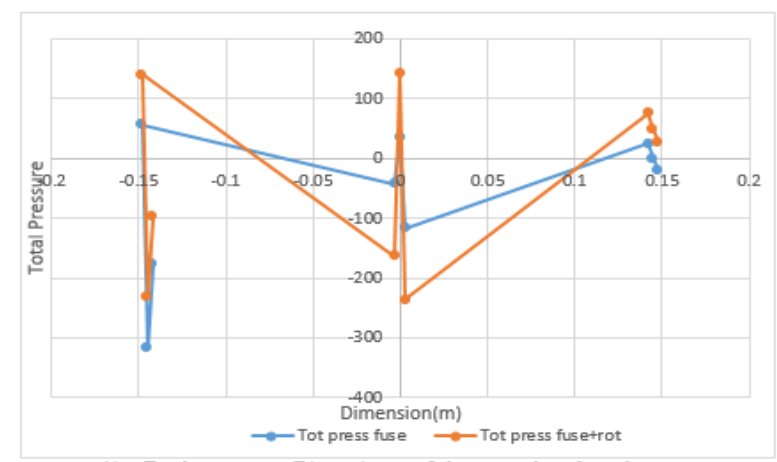

A) Total pressure vs Dimension on -5 degree angles of attack.

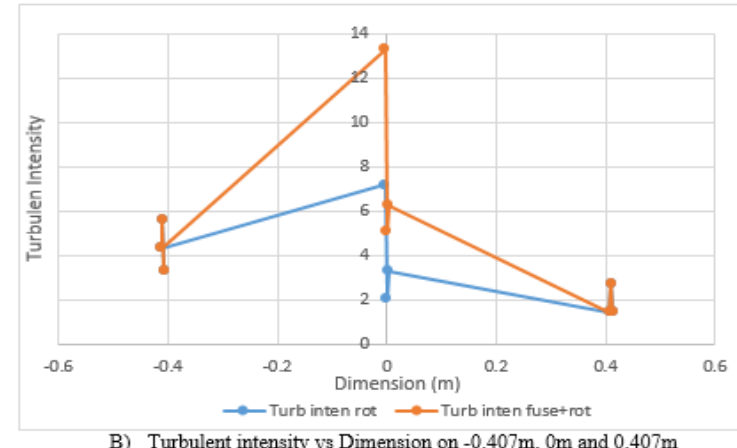

B) Turbulent intensity vs Dimension on $-0.407 \mathrm{~m}, 0 \mathrm{~m}$ and $0.407 \mathrm{~m}$

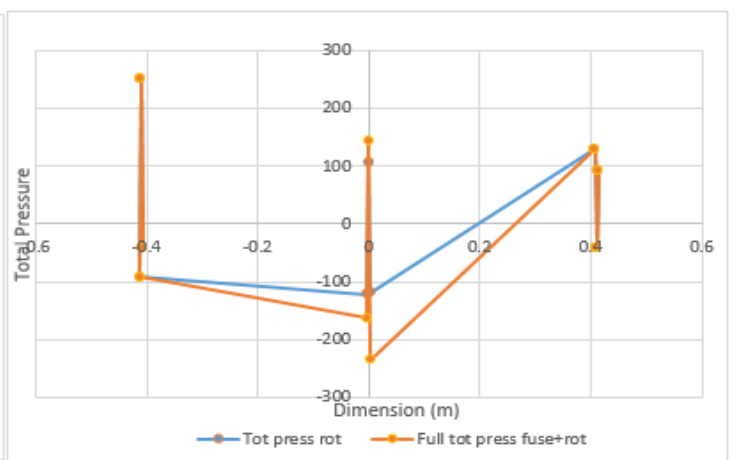

C) Total pressure vs Dimension on -5 degree angles of attack.

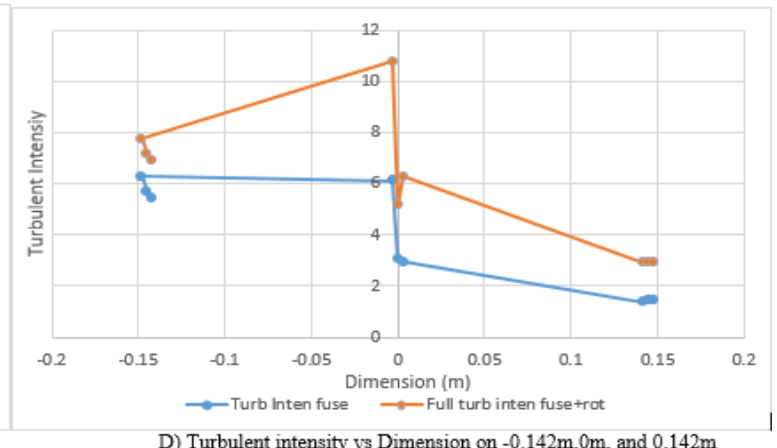

D) Turbulent intensity vs Dimension on $-0.142 \mathrm{~m}, 0 \mathrm{~m}$, and $0.142 \mathrm{~m}$

Fig. 8. Total pressure and turbulent intensity at an angle of attack of $-5^{\circ}$

Figure 9 shows significant colour differences that occurred behind the rotor and fairing, indicated that total adverse pressure occurred during the simulation.

Figure 10 presents the colour differences viewed during the turbulent or wake that happened during the simulation at $-5^{\circ}$ angle of attack.

Unsteady wake formation could be seen as the angle of attack increased mainly to significant changes in values of total pressure and turbulent intensity. This was due to the interference between the fairing with the body and the rotor with the fairing. It also verified the complexity of geometries 
affected the values of pressure and drag. The formation of adverse pressures occurred mostly around the area of the main rotor hub and fuselage. The bigger form of wake indicated a decrease in pressure adverse and turbulent intensity around the components.

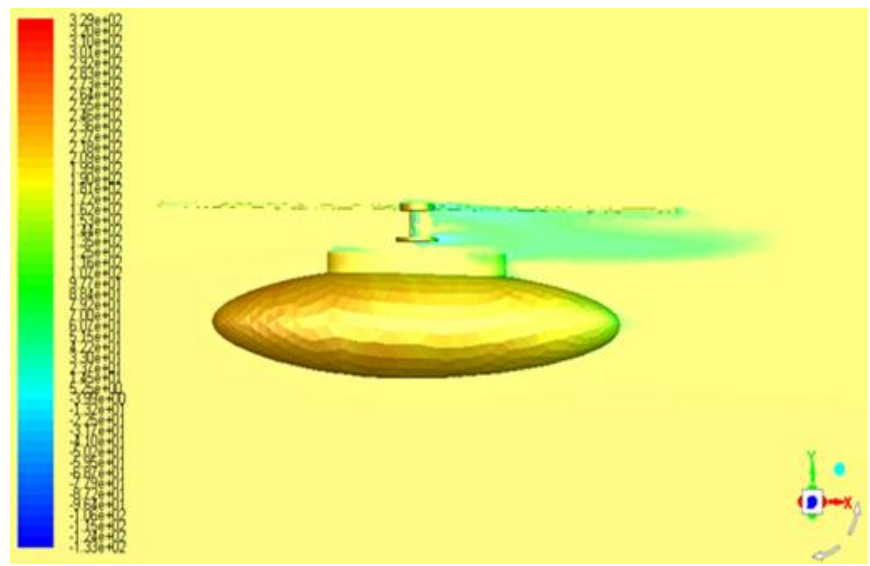

Fig. 9. The contour of total pressure at $-5^{\circ}$ angle of attack

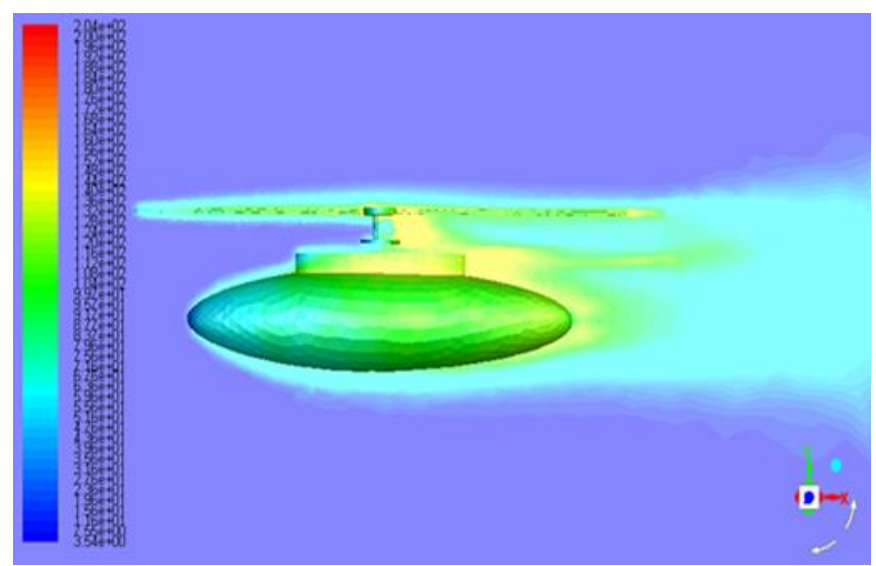

Fig. 10. The contour of turbulent intensity at $-5^{\circ}$ angle of attack

\section{Conclusions}

The simulation results of the simplified model helicopter using Ansys software have been presented. The outcomes testified the aerodynamic drag force increased by $14 \%$ from $0^{\circ}$ to $10^{\circ}$ angles of attack. As the helicopter angle of attack rose, it had been found that the complexity of the main rotor hub does play an important role in the formation of an unsteady wake at the rear end of the model. Results showed as the angle of attack increased, the rotor component caused additional drag force about $34 \%$ to $45 \%$ whilst the fuselage component contributed about $55 \%$ to $65 \%$ to drag increment. Moreover, as the simplified model noses down with an increased angle of attack, the frontal area also increased for the fuselage component but reduced at the blades stubs configurations that caused the up and down values of drag force between the two components. A significant increase in drag coefficient could be seen from the difference in range of increments angle of attack. The percentage of drag coefficient revealed rose between $20 \%$ and $55 \%$, from $0^{\circ}$ to $-20^{\circ}$ degree angles. Moreover, the range of value between $235 \mathrm{~Pa}$ to $250 \mathrm{~Pa}$ of total pressure and 10 to 13 highest values of turbulent intensity recorded for $-5^{\circ}$ angles of attack, showing the effect of the existence interference of fairing with body and fairing with a rotor, the complexity of geometries and 
angle of attacks produced drag and aft turbulence. Nonetheless, more experiments and simulations are needed to support and assist this complicated flow on a helicopter.

\section{Acknowledgement}

The authors would like to express gratitude to Aerolab UTM for providing valuable support to conduct this research project. The authors are also indebted to the UTM-Research University Grant, Tier 2 Vot Number Q.J130000.2651.16J33.

\section{References}

[1] Lombardo, D. C. "Helicopter structures-a review of loads, fatigue design techniques and usage monitoring." Technical Report 15, Department of Defence, Aeronautical Research Labs Melbourne (Australia), 1993.

[2] Keßler, Manuel, and Ewald Krämer. "Aeroelastic Simulation of the Tail Shake Phenomenon." Journal of the American Helicopter Society 63, no. 3 (2018). https://doi.org/10.4050/JAHS.63.032003

[3] Fraser, K. F. General Requirements and Techniques for Component Fatigue Life Substantiation in Australian Service Helicopters. Aeronautical Research Labs Melbourne (Australia), 1991.

[4] IVAO. "Wake Turbulence Separation Minima." International Virtual Aviation Organisation. Accessed October 24, 2017. https://mediawiki.ivao.aero/index.php?title=Wake turbulence separation minima.

[5] Hassan, Ahmed A., Thomas Thompson, Earl PN Duque, and John Melton. "Resolution of Tail Buffet Phenomena for $\mathrm{AH}-64 \mathrm{D}^{\mathrm{TM}}$ Longbow Apache ${ }^{\mathrm{TM}}$." Journal of the American Helicopter Society 44, no. 1 (1999): 16-25. https://doi.org/10.4050/JAHS.44.16

[6] Raghav, Vrishank, Rajiv Shenoy, Marilyn Smith, and Narayanan Komerath. "Investigation of drag and wake turbulence of a rotor hub." Aerospace Science and Technology 28, no. 1 (2013): 164-175. https://doi.org/10.1016/j.ast.2012.10.012

[7] Khier, Walid. "Numerical analysis of hub and fuselage interference to reduce helicopter drag." European Rotorcraft Forum (2012).

[8] Kasim, Khushairi Amri, Shabudin Mat, Iskandar Shah Ishak, and Mazuriah Said. "Effects of propeller locations on the vortex system above delta-shaped UAV model." In 30th Congress of The International Council of the Aeronautical Sciences, ICAS. 2016.

[9] Hall, Nancy. "Size Effects on Drag." National Aeronautics and Space Administration. Accessed October 23, 2017. https://www.grc.nasa.gov/www/k-12/airplane/sized.html.

[10] de Waard, Pieter, and Michel Trouve. "Tail shake vibration in flight- Objective comparison of aerodynamic configurations in a subjective environment." In AHS International Annual Forum, 55th, Montreal, Canada, pp. 23062316. 1999.

[11] Cassier, A., R. Weneckers, and J-M. Pouradier. "Aerodynamic development of the tiger helicopter." In Annual Forum Proceedings-American Helicopter Society, vol. 5, pp. 285-285. American Helicopter Society, 1994.

[12] Ishak, Iskandar Shah. "Unsteady Aerodynamic Wake Of Helicopter Main-Rotor-Hub Assembly." PhD diss., Universiti Teknologi Malaysia, 2012.

[13] Lorber, Peter F., and T. Alan Egolf. "An unsteady helicopter rotor: fuselage interaction analysis." NASA Contractor Report 4178 (1988).

[14] Khier, Walid. "Computational investigation of advanced hub fairing configurations to reduce helicopter drag." In 40th European Rotorcraft Forum, Southampton, UK. 2014.

[15] Stepanov, Robert, Vladimir Zherekhov, Vladimir Pakhov, Sergey Mikhailov, Aleksey Garipov, Walter Yakubov, and George N. Barakos. "Experimental study of helicopter fuselage drag." Journal of Aircraft 53, no. 5 (2016): 13431360. https://doi.org/10.2514/1.C033819

[16] Ishak, Iskandar Shah, Shuhaimi Mansor, Tholudin Mat Lazim, and Muhammad Riza Abd Rahman. "Numerical studies on unsteady helicopter main-rotor-hub assembly wake." Journal of Advanced Research in Fluid Mechanics and Thermal Sciences 47, no. 1 (2018): 190-200.

[17] Batrakov, A., L. Garipova, A. Kusyumov, S. Mikhailov, and G. Barakos. "Computational fluid dynamics modeling of helicopter fuselage drag." Journal of Aircraft 52, no. 5 (2015): 1634-1643. https://doi.org/10.2514/1.C033019

[18] Tu, Jiyuan, Guan Heng Yeoh, and Chaoqun Liu. Computational Fluid Dynamics: A Practical Approach. ButterworthHeinemann, 2012.

[19] ANSYS. "Cell Shape." Ansys Inc. Accessed $\quad$ October 20, 2017. http://www.afs.enea.it/project/neptunius/docs/fluent/html/ug/node167.htm.

[20] ANSYS. "Mesh Quality." Ansys Inc. Accessed October 14, 2017. https://slideplayer.com/slide/9559088/. 
[21] Wasserman, Shawn. "Choosing the Right Tubulence Model for Your CFD Simulation." Engineering.com. Accessed October 12 , 2017. https://www.engineering.com/DesignSoftware/DesignSoftwareArticles/ArticleID/13743/Choosing-the-RightTurbulence-Model-for-Your-CFD-Simulation.aspx.

[22] Ishak, Iskandar Shah, T. Mat Lazim, and Shuhaimi Mansor. "Wind Tunnel Tests on a Generic Eurocopter $350 z$ Helicopter." In 2nd Regional Conference on Vehicle Engineering \& Technology - RiVET', vol. 8. 2008. 